\title{
Heterokaryon Studies and the Genetic Control of Penicillin and Ghrysogenin Production in Penicillium chrysogenum
}

\author{
By K. D. MACDONALD, J. M. HUTCHINSON AND W. A. GILLETT \\ Microbiological Research Establishment, Porton, Salisbury, Wilts
}

(Received 20 June 1963)

\begin{abstract}
SUMMARY
A method of heterokaryon isolation with Penicillium chrysogenum is described where mycelium from mixed growth of two auxotrophs was fragmented and dispersed on a medium which only supported heterokaryon growth. This method overcomes the difficulties of producing heterokaryons in this organism which are ascribed to its slow growth rate. When heterokaryons grew they sometimes gave colonies which sectored from the centre into regions which, although still heterokaryotic, had widely different conidial ratios of each component strain. The nucleus was the major component in the inheritance of penicillin production but a minor effect was exerted through the cytoplasm. The yellow pigment, chrysogenin, produced by some strains of $P$. chrysogenum, was inherited as a nuclear-controlled character which was not a recessive trait.
\end{abstract}

\section{INTRODUCTION}

Difficulties in synthesizing heterokaryons of Penicillium chrysogenum were met when attempts were made by methods effective with Aspergillus nidulans. When a mesh of mycelium from mixed growth of two auxotrophs of $\boldsymbol{P}$. chrysogenum was plated on a medium which only supported heterokaryotic growth, heterokaryons rarely developed. It was suggested by Pontecorvo \& Sermonti $(1953,1954)$ and by Sermonti (1954) that, as a consequence of slow growth rate, 'staling' might occur in the medium before the emergence of heterokaryotic hyphae, and inhibit further growth. These authors found however that when conidia of two different dwarf mutants were plated together on a medium which supported their growth, heterokaryotic tufts of mycelium sometimes arose between genetically unlike colonies. The fact that growth of the component strains, although restricted, did take place tended to preclude staling, and also the heterokaryon when formed was not dwarfed and therefore had a selective advantage (Pontecorvo \& Sermonti, 1953, 1954). In later work Sermonti (1954) imposed the restrictions on growth of the component strains by environmental means. This method became the one of more general use with $\boldsymbol{P}$. chrysogenum.

In the method of heterokaryon isolation which is described in this paper mycelium which was the result of mixed growth between two auxotrophic parents was fragmented and dispersed in an agar medium selective for the heterokaryon. The direct exposure of heterokaryotic mycelium to a suitable environment would, it was hoped, allow it to grow free from staling.

With fungi where it can be used the heterokaryon test of Jinks $(1954,1956)$ can 


\section{K. D. Macdonald, J. M. Hutchinson and W. A. Gilletet}

show whether a character is inherited under nuclear or cytoplasmic control. When investigating the inheritance of penicillin production, Sermonti (1959) synthesized a heterokaryon between auxotrophs of Penicillium chrysogenum strains NRRL1951 and wis49-133 (see Fig. 1, Macdonald, Hutchinson \& Gillett, 1963; Backus \& Stauffer, 1955). Since penicillin yields remained in association with their nuclear markers after heterokaryon passage, Sermonti concluded that the changes towards increased penicillin production, accrued in the nine selection steps between NRRL1951 and wIS49-133, were mutations of nuclear origin. In view of the importance of this demonstration to a study of the genetics of penicillin production, confirmation was attempted in the work reported here by using for heterokaryon synthesis component strains of independent lineage and of relatively high penicillin yields. These were strains vo734 and 1754 which were more distantly related to strain NRRL1951 than strain wIS49-133 (see Macdonald et al. 1963).

Strains of Penicillium chrysogenum used in the early days of penicillin production liberated a yellow pigment, chrysogenin (Clutterbuck, Lovell \& Raistrick, 1932). The possibilities of breeding in $\boldsymbol{P}$. chrysogenum through parasexual processes (Pontecorvo \& Roper, 1952; Pontecorvo \& Sermonti, 1953, 1954) might include attempted crosses between pigment-producing and pigment-free strains. This focuses interest on the inheritance of chrysogenin production and a preliminary analysis is presented here.

\section{METHODS}

Only methods specific to the work described here are given below, otherwise methods, media and nomenclature are as detailed in the paper by Macdonald et al. (1963).

Strains. The mutants of Penicillium chrysogenum used in the investigations on heterokaryon isolation are shown in Table 1; those used in the work on the mode of inheritance of penicillin and chrysogenin production were:

\begin{tabular}{cll}
$\begin{array}{c}\text { Domestic } \\
\text { code }\end{array}$ & $\begin{array}{c}\text { Spore } \\
\text { colour }\end{array}$ & \multicolumn{1}{c}{$\begin{array}{c}\text { Growth factor } \\
\text { requirements }\end{array}$} \\
c51 & White & Biotin, proline \\
H55 & Brown & Thiamine, pyridoxin \\
D21 & Yellow & Leucine, thiamine/pyridoxin
\end{tabular}

For mutants with code prefix ' $\mathrm{C}$ ' the original prototrophic parental strain was VD734; with ' $D$ ', 1754; with ' $H$ ', NRRL1951; with ' $Y$ ', wis54-1255 (see Fig. 1, Macdonald et al. 1963). The mutants were isolated after successive treatments with ultraviolet radiation of the four original parents. A spore colour or auxotrophic mutation was imposed at each stage except in strain $\mathrm{D} \mathbf{2 1}$ where the final step in its derivation resulted in a double requirement, for thiamine + pyridoxin (Macdonald et al. 1963). Spore colour mutants were determined by autonomous factors (see Pontecorvo \& Sermonti, 1954).

Isolation of heterokaryons. A method of heterokaryon isolation similar to that used in Aspergillus nidulans (Pontecorvo, 1953) was compared with the method developed in our laboratory. The initial experimental manipulations were identical. One ml. of physiological saline was pipetted on to $10 \mathrm{ml}$. of complete medium (CM) agar contained in a $1 \mathrm{oz}$. McCartney bottle. Conidia from both component strains were inoculated together on the saline surface and the felt which was produced after 
4-5 days incubation at $25^{\circ}$ was removed, washed in saline and halved. It is here that the two methods of heterokaryon isolation diverge. (a) Aspergillus nidulans method. One half was further split into four portions and each teased out on to minimal medium (MM) agar. (b) Modified method. The other half was shaken in $5 \mathrm{ml}$. saline with a few $6 \mathrm{~mm}$. diam. glass beads and the suspension added to $100 \mathrm{ml}$. molten MM agar at about $45^{\circ}$ which was then poured into four plates.

Plates were incubated for 7 days and growth was either by extension round the original points of inoculum in the case of method $(a)$ or by the development of single colonies in the case of the method $(b)$. In both cases fresh isolations were made on MM agar by subcultivating mycelium from the extreme edge of a growing colony. In method $(a)$, when any one of the four pieces of mycelium inoculated on MM agar showed growth, a positive result of heterokaryosis was scored when a mycelial subculture made on the fresh MM agar produced a colony with conidia typical of both component strains. This was tested by streaking spores on CM agar and observing the colours of the colonies which developed. (Since in Penicillium chrysogenum conidia are uninucleate, individual colonies produced in this way will be homokaryons.) In the modified method $(b)$ the number of colonies which grew on MM agar after plating mycelial fragments varied from about ten to several hundred per plate. Usually four of these colonies were subcultured to fresh MM agar. A positive result was indicated here, when at least one subculture showed evidence of heterokaryosis by the method described above.

Inheritance of penicillin production. Cytoplasmic variation might occur between heterokaryons synthesized at different times. Conidia from CM agar slopes of strains C51 and D21 were inoculated together on to four bottles containing CM agar to ensure the independent origin of at least four heterokaryons. Six heterokaryons originating from each bottle were isolated on MM agar (i.e. 24 in all). The heterokaryons varied in conidial colour from a type resembling the white-sporing component strain c51 to a type resembling the yellow-sporing component strain D21. Sectoring, normally originating from the centre of the colony, was found in some of the heterokaryons so that these heterokaryotic colonies were sectored into 'white' and 'yellow' coloured regions. Within these larger sectors smaller peripheral sectors of green sporulation sometimes occurred; these proved to be heterozygous diploids when tested by the usual methods (Pontecorvo \& Roper, 1953). The 'white' and 'yellow' sectors were therefore presumed to be heterokaryotic.

Where heterokaryosis was completely confirmed by the occurrence of green heterozygous diploid regions, conidial samples were made from the various types of heterokaryons, plated on CM agar and counts made to estimate the proportion of white and yellow colonies, i.e. the proportion having strain c51 and strain D21 phenotype, respectively (Table 2). To test possible effects of cytoplasmic variation representative heterokaryons were chosen in which: (1) white and yellow conidia occurred in about equal proportions (heterokaryon IX); (2) white conidia predominated (heterokaryon VII); (3) yellow conidia predominated (heterokaryon XIVB). From each, conidia were plated on CM agar and after growth single-colony isolates were made on to $\mathrm{CM}$ agar slopes. In parallel, single-colony isolates were made in a similar way from conidia from each of the original slopes of strains c51 and D21 used in the preparation of the heterokaryons; these latter isolates served as controls.

Inheritance of chrysogenin production. A heterokaryon was synthesized between 


\section{K. D. Macdonald, J. M. Hutchinson and W. A. Grulett}

a pigment-free strain $\mathrm{c} 51$ and a chrysogenin-producing strain $\mathrm{H55}$. The heterokaryon produced was confirmed as such by the occurrence of green heterozygous diploid sectors. Conidia of the heterokaryon were plated on CM agar and as well as observing the ratio of one colony type to the other several single-colony isolates were made on to CM agar slopes, a proportion of which were tested for chrysogenin production (Table 4). It was found that growth in F-unit medium (see Macdonald et al. 1963) reliably distinguished pigment-producing strains from non-producers.

\section{RESULTS}

Eight pairs of nine mutants were examined for the production of heterokaryosis using both methods (Table 1). With the exception of the putative heterokaryons made between the last two pairs of strains in Table 1, heterozygous diploids were sought by the techniques of Pontecorvo \& Roper (1953), but only from heterokaryons isolated by the modified method $(b)$. It will be appreciated that where

Table 1. Comparison of methods of heterokaryon selection in Penicillium chrysogenum

\begin{tabular}{|c|c|c|c|c|c|}
\hline \multicolumn{3}{|c|}{ Component strains of heterokaryons } & $\begin{array}{l}\text { Aspergillus } \\
\text { nidulans } \\
\text { method }(a)\end{array}$ & \multicolumn{2}{|c|}{ Modified method $(b)$} \\
\hline $\begin{array}{l}\text { Domestic } \\
\text { code }\end{array}$ & $\begin{array}{l}\text { Spore } \\
\text { colour }\end{array}$ & $\begin{array}{c}\text { Growth } \dagger \\
\text { factor } \\
\text { requirement(s) }\end{array}$ & $\begin{array}{l}\text { Heterokaryon } \\
\text { provisionally } \\
\text { established }\end{array}$ & $\begin{array}{c}\text { Heterokaryon } \\
\text { provisionally } \\
\text { established }\end{array}$ & $\begin{array}{l}\text { Heterozygous } \\
\text { diploid } \\
\text { isolated }\end{array}$ \\
\hline $\begin{array}{l}\text { H54 } \\
\times 10\end{array}$ & $\begin{array}{l}\text { br } \\
\mathbf{w}\end{array}$ & $\left.\begin{array}{l}\text { thi } p d x \\
\text { nic }\end{array}\right\}$ & + & + & + \\
\hline $\begin{array}{l}\text { H54 } \\
\text { C13 }\end{array}$ & $\begin{array}{l}\text { br } \\
\mathbf{w}\end{array}$ & $\left.\begin{array}{l}\text { thi pdx } \\
\text { bio thio }\end{array}\right\}$ & - & + & + \\
\hline $\begin{array}{l}\mathrm{C} 42 \\
\mathrm{Y} 10\end{array}$ & $\begin{array}{l}\mathrm{y} \\
\mathrm{w}\end{array}$ & $\left.\begin{array}{l}\text { bio pro } \\
\text { nic }\end{array}\right\}$ & - & + & + \\
\hline $\begin{array}{l}\text { C43 } \\
\text { D12 }\end{array}$ & $\begin{array}{l}\mathrm{w} \\
\mathrm{y}\end{array}$ & $\left.\begin{array}{l}\text { bio thio } \\
\text { leu }\end{array}\right\}$ & - & + & + \\
\hline $\begin{array}{l}\text { c51 } \\
\text { y31 }\end{array}$ & $\begin{array}{l}\mathrm{w} \\
\mathrm{br}\end{array}$ & $\left.\begin{array}{l}\text { bio pro } \\
\text { bio nic }\end{array}\right\}$ & + & + & + \\
\hline $\begin{array}{l}\text { C51 } \\
\text { D12 }\end{array}$ & $\begin{array}{l}\mathrm{w} \\
\mathrm{y}\end{array}$ & $\left.\begin{array}{l}\text { bio pro } \\
\text { leu }\end{array}\right\}$ & + & + & + \\
\hline $\begin{array}{l}\text { Y9 } \\
\text { c13 }\end{array}$ & $\begin{array}{l}\text { br } \\
\text { w }\end{array}$ & $\left.\begin{array}{l}\text { nic } \\
\text { bio thio }\end{array}\right\}$ & - & + & * \\
\hline $\begin{array}{l}\text { Y9 } \\
\text { D6 }\end{array}$ & $\begin{array}{l}\text { br } \\
\mathrm{w}\end{array}$ & $\left.\begin{array}{l}\text { nic } \\
\text { thi }\end{array}\right\}$ & - & + & $*$ \\
\hline & $\begin{array}{r}{ }_{*}^{*} \text { Heterokar } \\
\dagger \mathrm{br}=\text { brow } \\
\mathbf{w}=\text { white } \\
\mathbf{y}=\text { yellor }\end{array}$ & $\begin{array}{r}\text { not tested for } \\
\text { bio }=\text { bioti } \\
\text { leu }=\text { leuci } \\
\text { nic }=\text { nicot }\end{array}$ & $\begin{array}{l}\text { oduction of het } \\
\text { pro } \\
\text { pdx } \\
\text { thide } \\
\end{array}$ & $\begin{array}{l}\text { rozygous diploic } \\
=\text { proline } \\
=\text { pyridoxin } \\
=\text { thiamine } \\
=\text { thiosulphate }\end{array}$ & \\
\hline
\end{tabular}

heterozygous diploids were not isolated, heterokaryosis was not unequivocally established by the test method used (spore streaking on CM agar) since a positive result might arise from syntrophic growth of both strains on MM agar. Nevertheless, the results in Table 1 confirm the findings of Pontecorvo \& Sermonti (1954) that method $(a)$ was not efficient with Penicillium chrysogenum and also show the success of method $(b)$. 
The results shown in Table 2 give conidial ratios of heterokaryons made between strains $\mathrm{C} 51$ and $\mathrm{D} 21$. While conidial ratios may not necessarily reflect, in strict proportions, nuclear ratios in the cytoplasm of a heterokaryon (Pontecorvo, 1953) it is believed that they give a good estimate (Jinks, 1952). By selecting extreme and intermediate heterokaryons as evidenced by conidial sampling, it was presumed that this would allow for the limits of cytoplasmic variation to be found under the experimental conditions used. Single-colony isolates derived from conidia of the three selected heterokaryons (heterokaryons VII, IX and XIVB) were tested for nutritional requirements. White-sporing isolates had the nutritional requirements

Table 2. Conidial ratios of heterokaryons made between Penicillium chrysogenum strains $\mathrm{C51}$ (white sporing) and D21 (yellow sporing)

Conidial ratios were scored by plating spores from a heterokaryotic colony on complete medium agar and counting the number of white and yellow colonies which grew. Only colonies established as heterokaryotic by the occurrence of heterozygous diploid sectors are listed below.

\begin{tabular}{|c|c|c|c|c|}
\hline $\begin{array}{l}\text { Bottle } \\
\text { no. }\end{array}$ & $\begin{array}{l}\text { Heterokaryon* } \\
\text { code }\end{array}$ & $\begin{array}{c}\text { Total } \\
\text { colonies } \\
\text { observed } \\
\text { (yellow } \\
\text { and } \\
\text { white) }\end{array}$ & $\begin{array}{l}\text { No. of } \\
\text { yellow } \\
\text { colonies }\end{array}$ & $\begin{array}{c}\% \\
\text { yellow } \\
\text { colonies }\end{array}$ \\
\hline 1 & $\begin{array}{l}\text { I } \\
\text { II }\end{array}$ & $\begin{array}{l}330 \\
260\end{array}$ & $\begin{array}{r}1 \\
224\end{array}$ & $\begin{array}{r}0 \cdot 3 \\
86 \cdot 2\end{array}$ \\
\hline 2 & $\begin{array}{l}\text { III } \\
\text { IV }\end{array}$ & $\begin{array}{r}359 \\
98\end{array}$ & $\begin{array}{r}349 \\
92\end{array}$ & $\begin{array}{l}97 \cdot 2 \\
93 \cdot 9\end{array}$ \\
\hline 3 & $\begin{array}{l}\text { V } \\
\text { VI } \\
\text { VII } \\
\text { VIII } \\
\text { IX }\end{array}$ & $\begin{array}{r}64 \\
48 \\
296 \\
216 \\
554\end{array}$ & $\begin{array}{r}9 \\
41 \\
7 \\
47 \\
368\end{array}$ & $\begin{array}{r}14 \cdot 8 \\
85 \cdot 5 \\
2 \cdot 4 \\
21 \cdot 8 \\
66 \cdot 4\end{array}$ \\
\hline 4 & $\begin{array}{l}\text { X } \\
\text { XI } \\
\text { XII } \\
\text { XIIIA } \\
\text { XIIIB } \\
\text { XIVA } \\
\text { XIVB }\end{array}$ & \begin{tabular}{r|r}
42 \\
183 \\
88 \\
.24 \\
223 \\
203 \\
103 \\
110
\end{tabular} & $\begin{array}{r}38 \\
178 \\
76 \\
6 \\
1 \\
0 \\
107\end{array}$ & \begin{tabular}{|c|}
$90 \cdot 0$ \\
$97 \cdot 3$ \\
$86 \cdot 4$ \\
$25 \cdot 0$ \\
$0 \cdot 4$ \\
0 \\
$97 \cdot 7$
\end{tabular} \\
\hline
\end{tabular}

* When heterokaryons originating from the same bottle and having the same roman numeral are listed as ' $A$ ' and ' $B$ ' this indicates that conidial sampling was done from two different sectors of the same heterokaryotic colony.

of strain $\mathrm{c51}$ and yellow-sporing isolates those of strain D21. The single-colony isolates made as controls from strains $\mathrm{c} 51$ and $\mathrm{D} 21$ all retained the spore colour and growth factor requirements of their parent strains. Each isolate was tested for penicillin yield in one fermentation against controls of strain D (Macdonald et al. 1963). In each experiment the control titre was the averaged performance of four separate fermentations. The penicillin productivity of each isolate is given in Table 3 as a yield index which was its titre expressed as a fraction of that of $D$ strain taken as unity.

There is little overlap in the titre distributions of single-colony isolates grown from conidia of strain $\mathbf{~ 5 1}$ and from conidia of strain D21 (Table 3). The modal titre 


\section{K. D. Macdonald, J. M. Hutchinson and W. A. Gilleett}

values differ by $0 \cdot 3$ yield index units. However, when component genomes were isolated subsequent to heterokaryon passage, then in all three cases the differences in modal titre values between isolates of $\mathrm{c51}$ and $\mathrm{D} 21$ types was decreased to $\mathbf{0 \cdot 2}$ yield index units. The evidence is that the decreased titre differences come about not by a unilateral movement of titre value of either type, but by a decrease in titre value of $\mathrm{D} 21$ types and an increase among c51 types (Table 3). However, the samples of $\mathbf{c 5 1}$ and D21 genomes obtained subsequent to heterokaryosis still remain as two distinct populations with regard to ability to produce penicillin.

Table 3. Distribution of penicillin yields among single-colony isolates of Penicillium chrysogenum strains $\mathrm{c51}$ and $\mathrm{D} 21$, made subsequent to the plating of dispersed conidia, and among single-colony isolates made following the plating of conidia of three different heterokaryons synthesized between strains $\mathrm{c} 51$ and $\mathrm{D} 21$

The titre of strain $D$ averaged about 4000 units penicillin/ml. on 6-day chemical assay.

No. of single-colony isolates in titre groups : strain $\mathrm{D}$ titre $=1$

\begin{tabular}{|c|c|c|c|c|c|c|c|c|c|c|c|c|c|c|}
\hline & & $\begin{array}{l}\text { Strain } \\
\text { type }\end{array}$ & & $\begin{array}{l}1.00 \\
0.91\end{array}$ & $\begin{array}{l}0.90 \\
0.81\end{array}$ & $\begin{array}{l}0.80 \\
0.71\end{array}$ & $\begin{array}{l}0 \cdot 70 \\
0 \cdot 61\end{array}$ & $\begin{array}{l}0.60 \\
0.51\end{array}$ & $\begin{array}{l}0.50 \\
0.41\end{array}$ & $\begin{array}{l}0 \cdot 40 \\
0 \cdot 31\end{array}$ & $\begin{array}{l}0.30 \\
0.21\end{array}$ & $\begin{array}{l}0 \cdot 20 \\
0 \cdot 11\end{array}$ & $\begin{array}{l}0 \cdot 10 \\
0\end{array}$ & Tot \\
\hline Controls & $\left\{\begin{array}{l}\text { Single- } \\
\text { colony } \\
\text { isolates }\end{array}\right.$ & $\left\{\begin{array}{l}\mathrm{C} 51 \\
\mathrm{D} 21\end{array}\right.$ & $\begin{array}{l}\left\{\begin{array}{l}\text { No. } \\
\%\end{array}\right. \\
\left\{\begin{array}{l}\text { No. } \\
\%\end{array}\right.\end{array}$ & $\begin{array}{l}. \\
20 \\
29 \cdot 0\end{array}$ & $\begin{array}{c}. \\
27 \\
39 \cdot 1\end{array}$ & $\begin{array}{c}. \\
18 \\
26 \cdot 1\end{array}$ & $\begin{array}{c}8 \\
13 \cdot 8 \\
4 \\
5 \cdot 8\end{array}$ & $\begin{array}{l}33 \\
56 \cdot 9 \\
. \\
.\end{array}$ & $\begin{array}{c}12 \\
20 \cdot 7 \\
. \\
.\end{array}$ & $\begin{array}{c}4 \\
6 \cdot 9 \\
\cdot \\
.\end{array}$ & $\dot{.}$. & $\begin{array}{c}1 \\
1 \cdot 7 \\
\cdot \\
.\end{array}$ & . & $\begin{array}{c}58 \\
6 \\
69 \\
.\end{array}$ \\
\hline $\begin{array}{l}\text { Heterokaryon } \\
\text { code }\end{array}$ & $\overbrace{\text { c51:D21 }}^{\begin{array}{c}\text { Conidial } \\
\text { ratios }\end{array}}$ & & & & & & & & & & & & & \\
\hline IX & $33 \cdot 6: 66 \cdot 4$ & $\left\{\begin{array}{l}c 51 \\
021\end{array}\right.$ & $\begin{array}{l}\left\{\begin{array}{l}\text { No. } \\
\%\end{array}\right. \\
\left\{\begin{array}{l}\text { No. } \\
\%\end{array}\right.\end{array}$ & $\begin{array}{l}\dot{4} \\
5 \cdot 7\end{array}$ & $\begin{array}{c}\cdot \\
10 \\
14 \cdot 3\end{array}$ & $\begin{array}{c}\dot{ } \\
40 \\
57 \cdot 1\end{array}$ & $\begin{array}{l}20 \\
28 \cdot 6 \\
13 \\
18 \cdot 6\end{array}$ & $\begin{array}{l}34 \\
48 \cdot 6 \\
3 \\
4 \cdot 3\end{array}$ & $\begin{array}{r}14 \\
20 \\
. \\
.\end{array}$ & $\begin{array}{l}2 \\
2 \cdot 9 \\
. \\
.\end{array}$ & $\dot{.}$ & . & . & $\begin{array}{l}70 \\
\dot{70}\end{array}$ \\
\hline VII & $97 \cdot 6: 2 \cdot 4$ & $\left\{\begin{array}{l}\mathrm{C51} \\
\mathrm{D} 21\end{array}\right.$ & $\begin{array}{l}\left\{\begin{array}{l}\text { No. } \\
\%\end{array}\right. \\
\left\{\begin{array}{l}\text { No. } \\
\%\end{array}\right.\end{array}$ & . & $\stackrel{\cdot}{3}$ & $\begin{array}{c}7 \\
9 \cdot 6 \\
1 \\
25 \cdot 0\end{array}$ & $\begin{array}{l}33 \\
45 \cdot 2 \\
. \\
.\end{array}$ & $\begin{array}{l}\mathbf{2 7} \\
\mathbf{3 7} \cdot 0 \\
\quad \cdot \\
.\end{array}$ & $\begin{array}{c}4 \\
5 \cdot 5 \\
\cdot \\
\cdot\end{array}$ & . & $\dot{.}$. & $\begin{array}{l}2 \\
2 \cdot 7 \\
. \\
.\end{array}$ & . & $\begin{array}{l}73 \\
\dot{4}\end{array}$ \\
\hline XIVB & $2 \cdot 3: 97 \cdot 7$ & $\begin{array}{l}\text { C51 } \\
\text { D21 }\end{array}$ & $\begin{array}{l}\left\{\begin{array}{l}\text { No. } \\
\%\end{array}\right. \\
\left\{\begin{array}{l}\text { No. } \\
\%\end{array}\right.\end{array}$ & $\begin{array}{l}\dot{.} \\
\dot{2} \\
2 \cdot 7\end{array}$ & $\begin{array}{l}\dot{ } \\
15 \\
20\end{array}$ & $\begin{array}{l}\dot{ } \\
31 \\
41 \cdot 3\end{array}$ & 13 & $\begin{array}{l}3 \\
75 \cdot 0 \\
10 \\
13 \cdot 3\end{array}$ & $\begin{array}{c}1 \\
25 \cdot 0 \\
2 \\
2 \cdot 7\end{array}$ & $\dot{.}$ & $\dot{.}$ & $\dot{.} \cdot$ & 2. & $\begin{array}{c}4 \\
75\end{array}$ \\
\hline
\end{tabular}

Difference in modal values between control isolates and isolates made subsequent to heterokaryon passage might be explicable in that the latter had gone through more nuclear divisions than the former, when traced back to the original slopes of c51 and D21 used in the experiment. Control isolates were made subsequent to the growth of single colonies from a plating of conidia from each slope. The other isolates were made following the plating of spores from heterokaryons and were further removed from the original slopes by the number of nuclear divisions which took place between mixed growth of the component strains on CM agar before heterokaryon formation and up to the production of conidia in the heterokaryons. This increased number of nuclear divisions might allow selection which was independent of heterokaryon passage to operate on nuclei. If so, the results in Table 3 would 
suggest that in the case of D21 types there was slight selection for decreased penicillin yield, and in the case of $\mathbf{c 5 1}$ types for increased yield. There is some evidence which suggests that continued nuclear division can lead to decreased penicillin yield (Macdonald, Hutchinson \& Gillett, unpublished), so that while the behaviour of D21 type isolates made after heterokaryon passage is not incompatible with a nuclear selection hypothesis it is believed that the behaviour of $\mathbf{c 5 1}$ type isolates is.

With respect to chrysogenin production it will be seen that, of several singlecolony isolates made subsequent to the growth of conidia from the heterokaryon between strains $\mathbf{C 5 1}$ and $\mathbf{H 5 5}$, all retained the growth factor requirements of the parent strain whose spore colour they imitated (Table 4). Among the proportion of these isolates tested the ability to produce chrysogenin remained in association with isolates of $\mathrm{H} 55$ type subsequent to heterokaryon passage, and no association with those of c51 type was demonstrated. A heterozygous diploid which was isolated from this heterokaryon also produced chrysogenin.

Table 4. Conidial ratio of a heterokaryon made between Penicillium chrysogenum strains $\mathrm{C51}$ (white sporing) and $\mathrm{H55}$ (brown sporing), phenotypes of single-colony isolates made subsequent to plating dispersed conidia of this heterokaryon and chrysogenin production among a proportion of these

$\begin{array}{lrlrr}\overbrace{\text { Colour }}^{2} \text { No. } & & \overbrace{\text { Colour }} & \text { No. } & \text { Phenotype } \\ \text { White } & 36 & \text { White } & 28 & \text { All c51 typ } \\ \text { Brown } & 204 & \text { Brown } & 109 & \text { All H55 typ }\end{array}$

\begin{tabular}{|c|c|c|}
\hline Phenotype & No. & $\begin{array}{c}\text { No. of } \\
\text { chrysogenin } \\
\text { producers }\end{array}$ \\
\hline c51 & 22 & $\mathbf{0}$ \\
\hline H55 & 70 & 70 \\
\hline
\end{tabular}

\section{DISCUSSION}

Technically the new method of heterokaryon isolation is at least as easy as the method of Sermonti. Unlike his technique, no special media are required; neither minimal medium (MM) agar with limited additions of growth factors (Sermonti, 1954), nor, as he has used in later work, complete medium (CM) diluted with MM (Sermonti, 1956) are needed. The new method has the advantage that certain auxotrophs which cannot be used as parent strains in Sermonti's method can now be used. These are auxotrophs which, instead of showing a progressive restriction in colony size as the amount of growth factor in the medium is decreased, show a progressive diminution in colony numbers (Sermonti, 1954; Macdonald, unpublished).

As evidenced by sectoring in single colonies, heterokaryons of widely different nuclear ratios were able to exist under what were apparently uniform environmental conditions. The shapes of such sectors in a heterokaryotic colony suggested that they did not differ in growth rates (see Pontecorvo \& Gemmell, 1944). Since the heterokaryotic sectors could grow from the centre of a colony, the difference between them must have been established in the early stages of growth and thereafter maintained throughout the growth period of the colony, suggesting a lack of selection for a particular nuclear ratio. To explain the origin of sectoring, it should be mentioned that in our work no attempt was made to transfer heterokaryons by means of single hyphal tips in order to ensure the heterokaryotic nature of a colony; the occurrence of heterozygous diploids was taken as evidence of this. A small 


\section{K. D. Macdonald, J. M. Hutchinson and W. A. Gillett}

piece of mycelium from the colony edge of a putative heterokaryon was used to initiate each heterokaryon. This inoculum could be visualized as several growing points exposed for radial growth. Heterokaryotic hyphal tips exposed to fresh MM agar would presumably grow out, and have the same nuclear ratios as the heterokaryon from which inoculum was made. However, Rees \& Jinks (1952) suggested that, in heterokaryons growing under uniform conditions, although the overall ratio of nuclear types might be constant it might vary in cells behind those at the hyphal tips; such cells contain fewer nuclei than hyphal-tip cells. Therefore, if by mechanical injury or otherwise viable cells other than hyphal-tip cells were exposed for growth, then they might grow out with the nuclear ratios they happened to have. Attempts might be made to confirm this suggestion by discovering whether inoculations from 'white' and from 'yellow' heterokaryons both gave rise to 'white' and 'yellow' sectored heterokaryons.

Jinks (1956, 1957) showed that characters such as germination and growth rates could be inherited under cytoplasmic influence in Aspergillus glaucus, $A$. nidulans and Penicillium cyclopium. Such traits or others inherited under cytoplasmic influence might affect penicillin titre, and it would perhaps be surprising if a character so sensitive to change in the external environment remained completely unaffected by cytoplasmic differences. The evidence presented here points to a cytoplasmic influence on the inheritance of penicillin productivity, but this is a minor effect in comparison with that exerted by the nucleus. The results therefore largely support those of Sermonti (1959) and justify investigation of the inheritance of penicillin production via the parasexual mechanism.

The mode of inheritance of chrysogenin production as a nuclear character confirms the result of Sermonti \& Morpurgo (1959): a heterozygous diploid synthesized between strains $\mathbf{c 5 1}$ and $\mathrm{H} 55$ liberated chrysogenin, so that pigment production was not inherited as a recessive trait. Details of segregants obtained from this diploid which it is hoped to publish later suggest that chrysogenin production is inherited as a character under chromosomal control.

Our thanks are due to Dr D. W. Henderson, F.R.S., for his continued encouragement and to Professor J. A. Roper and Dr T. W. Burrows for helpful discussion. We are also indebted to Mr E. W. Harris and Miss Marion Stubbs who at different times gave expert technical assistance. This work was financed by the National Research Development Corporation.

\section{REFERENCES}

Backus, M. P. \& Stauffer J. F. (1955). The production and selection of a family of strains in Penicillium chrysogenum. Mycologia, 47, 429.

Clutterbuck, P. W., Loveli, R. \& Raistrick, H. (1932). cexxvii. Studies in the biochemistry of micro-organisms. xxvi. The formation from glucose by members of the Penicillium chrysogenum series of a pigment, an alkali-soluble protein and penicillin, the antibacterial substance of Fleming. Biochem. J. 26, 1907.

Jinks, J. L. (1952). Heterokaryosis: a system of adaptation in wild fungi. Proc. roy. Soc. B, $140,83$.

Jinks, J. L. (1954). Somatic selection in fungi. Nature, Lond. 174, 409.

JiNks, J. L. (1956). Naturally occurring cytoplasmic changes in fungi. C.R. Lab. Carlsberg Ser. physiol. 26, 183. 
Jinks, J. L. (1957). Selection for cytoplasmic differences. Proc. roy. Soc. B, 146, 527.

Macdonald, K. D., Hutchinson, J. M. \& GiLletT, W. A. (1963). Isolation of auxotrophs of Penicillium chrysogenum and their penicillin yields. J. gen. Microbiol. 33, 365.

Ponteconvo, G. (1953). Heterokaryosis. Advanc. Genet. 5, 176.

Pontecorvo, G. \& Gemmell, A. R. (1944). Colonies of Penicillium notatum and other moulds as models for the study of population genetics. Nature, Lond. 154, 532.

Pontecorvo, G. \& Roper, J. A. (1952). Genetical analysis without sexual reproduction by means of polyploidy in Aspergillus nidulans. J. gen. Microbiol. 6, vii.

Ponteconvo, G. \& Roper, J. A. (1953). Diploids and mitotic recombination. Advanc. Genet. 5, 218.

Pontecorvo, G. \& Sermontr, G. (1953). Recombination without sexual reproduction in Penicillium chrysogenum. Nature, Lond. 172, 126.

Pontecorvo, G. \& Sermonti, G. (1954). Parasexual recombination in Penicillium chrysogenum. J. gen. Microbiol. 11, 94.

ReEs, H. \& JiNks, J. L. (1952). The mechanism of variation in Penicillium heterokaryons. Proc. roy. Soc. B, 140, 100.

Sermonti, G. (1954). Genetics of Penicillium chrysogenum. 1. Heterokaryosis in Penicillium chrysogenum. R.C. Ist. sup. Sanit. (English edition), 17, 213.

Sermontr, G. (1956). Complementary genes which affect penicillin yields. J. gen. Microbiol. 15, 599.

Sermonti, G. (1959). Genetics of Penicillium chrysogenum. iii. Cytoplasmic inheritance in Penicillium. Sel. Sci. Pap. Ist. sup. Sanit. 2, 407.

SERmonti, G. \& Morpurgo, G. (1959). Trasmissione citoplasmatica del carattere 'nanismo' in Penicillium chrysogenum. 'Conv. di Genetica 1957'. Ricerca Sci. 29, 171. 